\title{
Control of reactive distillation process for production of ethyl acetate
}

\author{
Hao-Yeh Lee ${ }^{\text {a }}$, Hsiao-Ping Huang ${ }^{\text {a,* }}$, I-Lung Chien ${ }^{\mathrm{b}}$ \\ a Department of Chemical Engineering, National Taiwan University, Taipei 10617, Taiwan, ROC \\ ${ }^{\mathrm{b}}$ Department of Chemical Engineering, National Taiwan University of Science and Technology, Taipei 10617, Taiwan, ROC
}

Received 12 October 2005; received in revised form 4 August 2006; accepted 3 October 2006

\begin{abstract}
In this paper, plant-wide control for the production of ethyl acetate using reactive distillation is studied. Four important issues are considered in developing control schemes, including: (1) economics; (2) steady-state deviation of key product purities; (3) controllability in terms of degree of oscillation and settling time; and (4) feasible region of disturbances for effective control. Starting with two basic control schemes that have been studied before, new control schemes are developed to improve the operability of the process. These new control schemes have evolved from the basic schemes by making a trade-off between optimal design and control or by selecting sensor locations using closed-loop sensitivity analysis. It is found that, while being subjected to fluctuations in the composition of the acid feed or in the production flow-rate, sensor location based on traditional open-loop sensitivity causes a larger overshoot and steady-state deviation of key product purities. Sensor location on the basis of a closed-loop sensitivity analysis provides a better alternative for feedback control. The resulting scheme for control is found to be effective in reducing the steady-state deviation and in promoting good control performance.
\end{abstract}

(c) 2006 Elsevier Ltd. All rights reserved.

Keywords: Reactive distillation; Closed-loop sensitivity analysis; Operability range

\section{Introduction}

Reactive distillation (RD) for the production of ethyl acetate (EtAc) has been used for a number of years. There are many studies on RD in the literature; however, very few of these studies have addressed control issues. The work by Burkett and Rossiter [1] is one of the few reports in the literature. They studied an industrial RD column in which the reaction took place at the column base. The control study was focused on the RD column alone (not considering plant-wide control), and the composition of the EtAc product from the top of the column was not pure enough to be of commercial use. Later, Vora and Daoutidis [2] reported work on the operation and control of a single EtAc RD column. A single column was found to be unable to produce EtAc of sufficient purity, and subsidiary units

\footnotetext{
${ }^{*}$ Corresponding author. Tel.: +88622363 8999; fax: +886223623935.

E-mail address: huanghpc@ntu.edu.tw (H.-P. Huang).
}

were needed. Their study of control was not in the sense of plant-wide control. Recently, Tang et al. [3] proposed a complete process for the production of EtAc using RD. The process includes two columns (RD and stripper), one decanter, and two recycle streams. The process delivered a high-purity EtAc product with a stringent impurity specification. Tang et al. [4] studied plant-wide control with four schemes based on this process. The simplest one was the single-point control scheme, which has a fast settling time following fluctuations of throughput and feed composition. However, the drawback of this scheme is a large overshoot and the possibility of steady-state deviation in product purity. Although another scheme with RD dualpoint control that they recommended can overcome these problems, the process responses become more oscillatory. Thus, the design of a control system for this process is very problematic.

Here, we investigate the means for better control of the production of EtAc by RD. Different control schemes, 
including the original single-point and dual-point control schemes described by Tang et al. [4] are investigated and compared. This study is focused on the following four important issues: (1) steady-state economics of the alternative base case condition; (2) steady-state closed-loop behavior of the final product purities; (3) dynamic controllability in terms of degree of oscillation and closed-loop settling time; and (4) feasible region of disturbances, such as throughput and HAc composition in feed, for effective control. The target objectives in the product stream are purity of $\mathrm{EtAc}>99.5$ wt.\%; $\mathrm{HAc}<0.01$ wt.\%; and $\mathrm{EtOH}<$ 0.2 wt. $\%$. An effective control means the system is able to keep the product stream within specifications mentioned in all cases, despite the occurrence of disturbances.

This paper is arranged as follows. A summary on the previous design and control of the RD process for EtAc [4], thermodynamic properties, reaction kinetics model, and the base case design are given in Section 2. The inventory control loops together with the control performance of the original single-point and dual-point control schemes are given in Section 3. In Section 4, a trade-off between the optimal design and dynamic controllability is made to the single-point control scheme. Dynamics and control are thus compared with those from the original paper [4]. Also in Section 4, closed-loop sensitivity analysis is conducted to identify more suitable alternative sensor locations for temperature control. The control performance with this alternative selection of the control point(s) are presented in this section. Operability range analysis for the above control schemes are discussed in Section 5. On the basis of the results obtained, another control scheme is proposed to improve the operability range of single-point control. Our concluding remarks are given in Section 6.

\section{Design of the base case}

\subsection{Thermodynamic and kinetic models}

The thermodynamic model used in this study is the same as that used by Tang et al. [3]. There are four azeotropes in this system; three homogeneous azeotropes of EtOH-EtAc,
EtOH- $\mathrm{H}_{2} \mathrm{O}$, and EtOH-EtAc- $\mathrm{H}_{2} \mathrm{O}$, and one heterogeneous azeotrope of EtAc- $\mathrm{H}_{2} \mathrm{O}$. The parameters of a nonrandom two-liquid (NRTL) model have been established to predict the composition and temperature of the four azeotropes. Vapor association of HAc due to dimerization has been included by using the second virial coefficient of the Hayden-O'Connell [5] model in the vapor phase. The complete set of NRTL parameters is given by Table 1 .

The kinetic model for this chemical reaction system is adopted from that described by Alejski and Duprat [6] The model consists of two sets of parameters: one is for the reaction with sulfuric acid as a homogeneous catalyst; and the other is for the reaction without a catalyst. The kinetic equations in the model are

With sulfuric acid as homogeneous catalyst:

$r_{1}=k_{1} C_{\mathrm{HAc}} C_{\mathrm{EtOH}}-\frac{k_{1}}{K_{\mathrm{c}}} C_{\mathrm{EtAc}} C_{\mathrm{H}_{2} \mathrm{O}}$

$k_{1}=\left(4.195 C_{k}+0.08815\right) \exp (-6500.1 / T)$

$K_{\mathrm{c}}=7.558-0.012 T$

where $k_{1}$ is the forward reaction rate constant (in $\mathrm{m}^{3} / \mathrm{mol}$ ) $\mathrm{s}), T$ is the temperature (in $\mathrm{K}$ ), and $C_{k}$ is the catalyst concentration (in vol\%), and all of the other concentrations in Eqs. (1)-(3) are in $\mathrm{mol} / \mathrm{m}^{3}$.

\section{Without catalyst:}

$r_{1}=k_{1} C_{\mathrm{HAc}} C_{\mathrm{EtOH}}-k_{2} C_{\mathrm{EtAc}} C_{\mathrm{H}_{2} \mathrm{O}}$

$k_{1}=0.485 \exp (-59,774 / R T)$

$k_{2}=0.123 \exp (-59,774 / R T)$

where $R$ is the gas constant (in $\mathrm{J} /(\mathrm{mol} \mathrm{K})$ ).

\subsection{The base case design}

The steady-state design of the RD process described here is based on the work by Tang et al. [3], in which the optimal design was achieved through a rigorous optimizing procedure using Aspen Plus ${ }^{\circledR}$ [7]. Since the EtOH-EtAc$\mathrm{H}_{2} \mathrm{O}$ azeotrope has the lowest temperature, it will leave the top of the RD column first. However, this azeotrope is not suitable for separation to obtain a high-purity prod-

Table 1

NRTL model parameters ${ }^{\mathrm{a}}$ [6]

\begin{tabular}{|c|c|c|c|c|c|c|}
\hline $\begin{array}{l}\text { Comp. } i \\
\text { Comp. } j\end{array}$ & $\begin{array}{l}\mathrm{HAc}(1) \\
\operatorname{EtOH}(2)\end{array}$ & $\begin{array}{l}\operatorname{HAc}(1) \\
\operatorname{EtAc}(3)\end{array}$ & $\begin{array}{l}\mathrm{HAc}(1) \\
\mathrm{H}_{2} \mathrm{O}(4)\end{array}$ & $\begin{array}{l}\operatorname{EtOH}(2) \\
\operatorname{EtAc}(3)\end{array}$ & $\begin{array}{l}\mathrm{EtOH}(2) \\
\mathrm{H}_{2} \mathrm{O}(4)\end{array}$ & $\begin{array}{l}\operatorname{EtAc}(3) \\
\mathrm{H}_{2} \mathrm{O}(4)\end{array}$ \\
\hline$a_{i j}$ & 0 & 0 & -1.9763 & 1.817306 & 0.806535 & -2.34561 \\
\hline$a_{j i}$ & 0 & 0 & 3.3293 & -4.41293 & 0.514285 & 3.853826 \\
\hline$b_{j i}$ & 225.4756 & 515.8212 & -723.888 & 1614.287 & 444.8857 & -4.42868 \\
\hline$\alpha_{i j}$ & 0.3 & 0.3 & 0.3 & 0.1 & 0.4 & 0.364313 \\
\hline
\end{tabular}

${ }^{\mathrm{a}}$ NRTL model:

$\ln \gamma_{i}=\frac{\sum_{j=1}^{n c} \tau_{j i} G_{j i} X_{j}}{\sum_{k=1}^{n c} G_{k i} X_{k}}+\sum_{j=1}^{n c} \frac{X_{j} G_{j i}}{\sum_{j=1}^{n c} G_{k j} X_{k}}\left[\tau_{i j}-\frac{\sum_{k=1}^{n c} X_{k} \tau_{k i} G_{k j}}{\sum_{k=1}^{n c} G_{k j} X_{k}}\right]$

$G_{i j}=\exp \left(-\alpha_{i j} \tau_{i j}\right), \tau_{i j}=a_{i j}+b_{i j} / T(\mathrm{~K}), \alpha_{i j}=\alpha_{j i}$ and $\tau_{i j}=\tau_{j i}=0$. 
uct. The second lowest temperature azeotrope is the binary EtAc- $\mathrm{H}_{2} \mathrm{O}$ mixture, which has a heterogeneous phase split. The EtAc- $\mathrm{H}_{2} \mathrm{O}$ azeotrope is suitable to be the top vapor from the RD column, because, after phase splitting in the decanter, the organic phase EtAc composition will become much purer. In reality, the overhead vapor composition will be kept somewhere between these two azeotropes, and preferably stay inside the heterogeneous phase splitting region.

The flow-chart for the optimal design is shown in Fig. 1 It includes an RD column with a decanter and a stripping column. The vapor from the RD column is taken to an overhead decanter, where the vapor is condensed and split into two phases. As shown in the flow-chart, the aqueous phase containing mostly water is drawn out of the process as waste. Part of the organic phase is recycled to the RD column as an entrainer to carry water toward the top of the column, and the rest of the organic phase is fed into the stripping column for further purification. The bottom product stream of the RD column is designed to be rich in HAc, so that it can be recycled along with the fresh feed of HAc to the RD column. The top product of the stripper column is also returned to the decanter. In order to guarantee liquid-splitting, an additional water flow to the decanter is needed to achieve high-purity EtAc in the bottom of the stripper column. The final bottom stream of the stripper column consists of EtAc with a purity $>99.5 \mathrm{wt} . \%$. The contents of the HAc and EtOH impurities in the final EtAc product have two specifications: the HAc target is $<0.01 \mathrm{wt} . \%$ and the $\mathrm{EtOH}$ target is $<0.2 \mathrm{wt} . \%$.

The EtOH feed flow-rate of the base case is taken from the work by Vora and Daoutidis [2] as $6.865 \mathrm{~mol} / \mathrm{s}$, and the contents of the HAc and $\mathrm{EtOH}$ feeds are $95.2 \mathrm{~mol} \%$ and $82.2 \mathrm{~mol} \%$, the same as those used by Alejski and Duprat [6]. The HAc feed flow-rate is $5.65 \mathrm{~mol} / \mathrm{s}$, as determined by Tang et al. [3]. Notice that both of these feed streams contain some water. The pure EtOH/HAc molar feed ratio is about 1.05; therefore, excess EtOH is fed into the RD column. The concentration of the catalyst in Eq. (2) is assumed to be $0.4 \mathrm{vol} \%$, as used by Alejski and Duprat [6]. Since this concentration of catalyst is quite low, it is neglected in the calculation of vapor-liquid equilibrium, and is considered to be circulating between the HAc feed stage and the bottom of the RD column. In the resulting EtAc process, the total number of trays in the RD column and in the stripper column are 29 and 11, respectively, and the HAc and EtOH feed location are on the 10th and 28th tray, respectively.

We used the Aspen Dynamics ${ }^{\mathrm{TM}}$ to study the dynamics and control of the process [8]. The RD column has a diameter of $3 \mathrm{~m}$ and the weir for each tray is $0.1524 \mathrm{~m}$ high. The equilibrium stage model is used in the simulation with bubble cap stages, and the holdup volume in each tray is approximately $1 \mathrm{~m}^{3}$. The residence time of each tray is about 4-5 min. This design is intended to have a high liquid holdup and liquid-phase residence time so that the regime

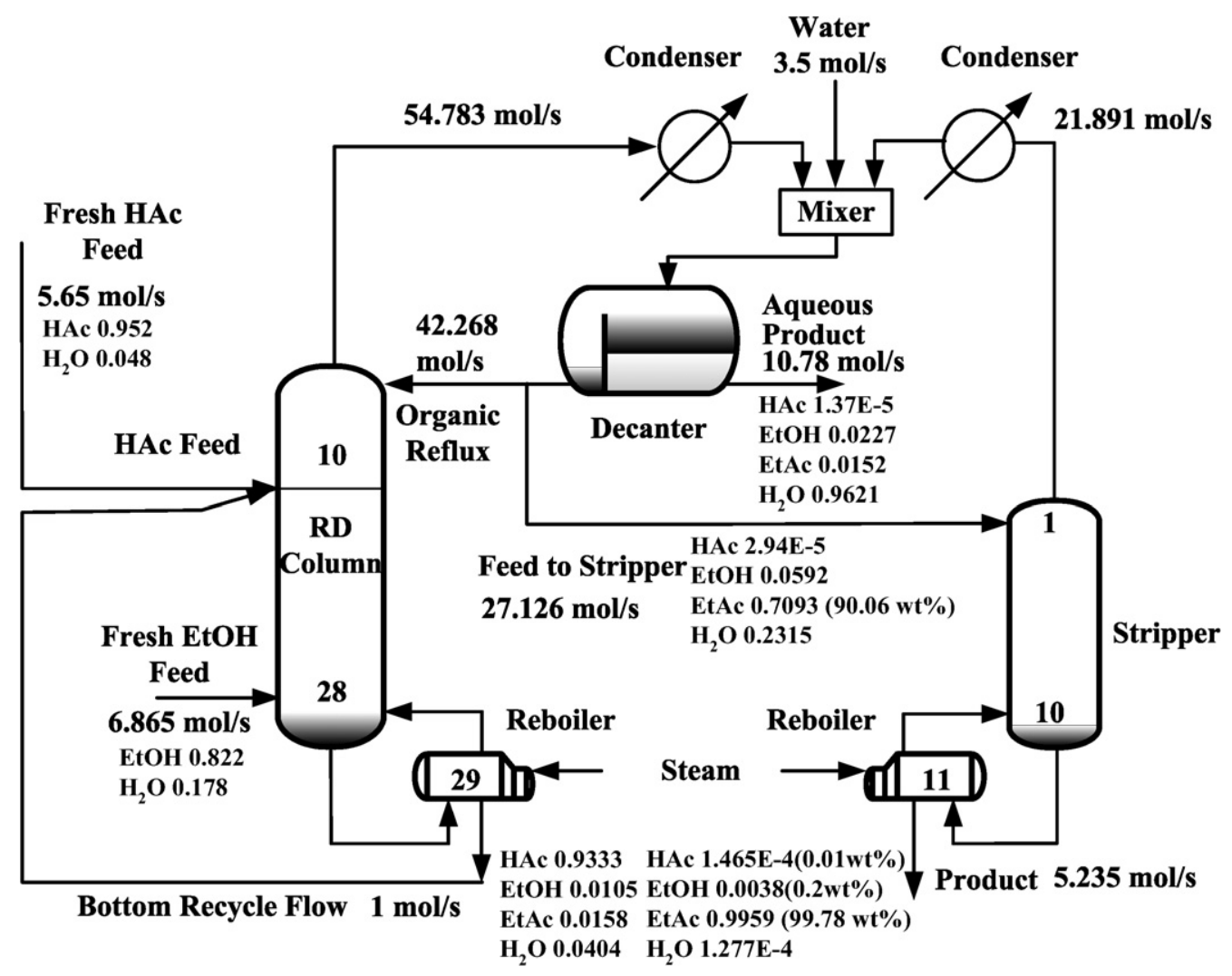

Fig. 1. Configuration of the complete EtAc RD process [3] 
of operation at each tray is in the bubbly flow regime, in agreement with the suggestion made by Krishna [9].

\section{Basic control structures}

The control objectives are to keep the product stream contents of HAc and EtOH at $<0.01 \mathrm{wt} . \%$ and $<0.2 \mathrm{wt} . \%$, respectively, in order to meet industrial specifications. The flow-rate of fresh EtOH feed in Fig. 1 is designed to be the throughput regulator of the overall process. Whenever the required production rate increases or decreases, the fresh EtOH feed flow-rate will be changed to accommodate this need.

\subsection{Inventory control loops}

In this EtAc process, there are six inventory control loops. These include the control of four levels (the bottom of the RD column, the organic phase in the decanter, the aqueous phase in the decanter, and the bottom of the stripping column), the top pressure of the RD column and the top pressure of the stripping column. The inventory loops are arranged as follows. The level of the organic phase in the decanter is controlled by manipulating the feed flow to the stripper column, and the level of the aqueous phase is controlled by the aqueous outlet flow. The bottom level of the stripper column is controlled by the final EtAc product flow, and the bottom level of the RD column is controlled by manipulating the reboiler. Both top pressures are controlled by manipulating the vapor flow at the top outlet.

Other control loops required besides the inventory loops include: maintaining the temperature of the decanter at $40{ }^{\circ} \mathrm{C}$, which is controlled by manipulating the cooling of the decanter. The temperature of the stream from the top of the RD column and from the top of the stripping column after the condenser is maintained at $40{ }^{\circ} \mathrm{C}$ by manipulating the condenser.

\subsection{Quality control loops}

The variables that can be used for quality control are: the fresh $\mathrm{HAc} / \mathrm{EtOH}$ feed ratio, the organic reflux ratio, the stripper reboiler duty, and the fresh water feed to the decanter. Only two or three of these variables are used to form quality control loops. The fresh water feed to the decanter is not used in the quality control loops due to the low sensitivity of product quality to it. It will be used, nevertheless, as an economic variable and a safety variable to guarantee the liquid phase splitting in the decanter. One or two tray temperatures in the RD column and one tray temperature in the stripper are selected as the variables to be controlled to guarantee the quality of the EtAc product stream within specifications. The temperature control point in the RD column is important, as it affects the composition of HAc in the vapor stream at the top of the RD column. Because HAc has the highest boiling point in the system, this impurity is carried over from the RD column to the final product stream. The temperature control point in the stripper column is sensitive to the purity of $\mathrm{EtOH}$ in the final product stream.

Two best control schemes of Tang et al. [4] are first studied. In both control schemes, the locations of temperature sensors are determined by an open-loop sensitivity analysis. The results given in Fig. 2 show the sensitivities of the RD and stripper columns subjected to changes of the fresh $\mathrm{HAc} / \mathrm{EtOH}$ feed ratio, the organic reflux ratio, and the stripper reboiler duty. The results show that the temperature at the 4th tray of the RD column is the most sensitive to changes of the $\mathrm{HAc} / \mathrm{EtOH}$ feed ratio. As a result, the fresh $\mathrm{HAc} / \mathrm{EtOH}$ feed ratio is a potential variable to be used to control the temperature in the RD column. The temperature of the 6th tray in the stripper column in Fig. 2 is a feasible control point to manipulate the stripper reboiler duty. As there is only one temperature loop in the $\mathrm{RD}$ column for the control of quality, this configuration is considered a single-point control for the RD column, and is referred to as the CS1A scheme.

There is another degree of freedom organic reflux ratio in manipulated variables, and a dual-point control for the $\mathrm{RD}$ column which is referred to as the CS2A scheme later
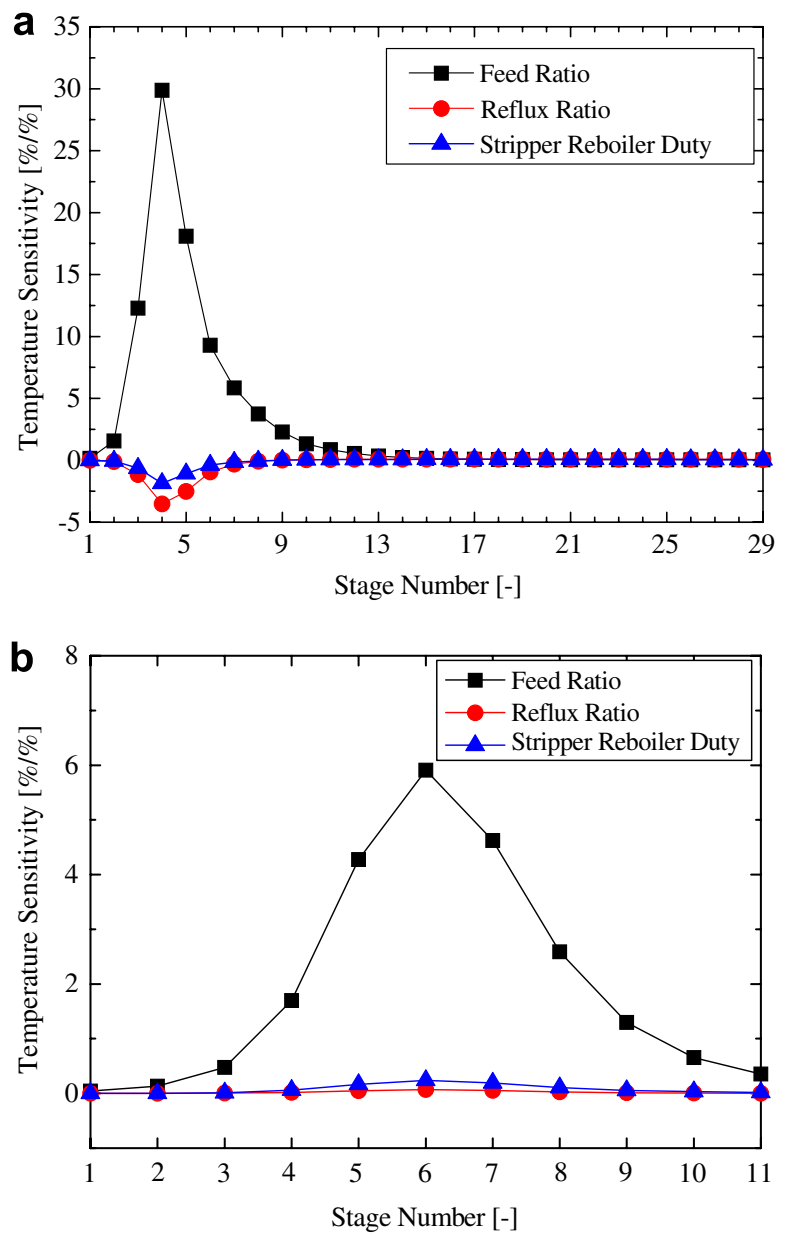

Fig. 2. Open-loop sensitivity analysis for (a) RD column, and (b) stripper. 
on was studied by Tang et al. [4]. Notice that these two temperature control locations were determined from a modified principal component analysis [10]. This method is based on the singular value decomposition (SVD) analysis. In Eqs. (7) and (8), the left singular vectors $U$ can be obtained and the results are shown in Fig. 3

$K=U \Sigma V^{\mathrm{T}}$

$K=\left[\begin{array}{cc}\frac{\partial T_{1}}{\partial F R} & \frac{\partial T_{1}}{\partial R R} \\ \frac{\partial T_{2}}{\partial \mathrm{FR}} & \frac{\partial T_{2}}{\partial \mathrm{RR}} \\ \vdots & \vdots \\ \frac{\partial T_{n}}{\partial \mathrm{FR}} & \frac{\partial T_{n}}{\partial \mathrm{RR}}\end{array}\right]$

The largest and smallest singular values $\left(\sigma_{1}=30.3154\right.$, $\sigma_{2}=0.3472$ ) can be obtained by Eq. (7). Because the sensor locations from the SVD analysis are at the 4th and 5th trays of the RD column, which are too close and they exhibit large interactions, the modification variable $Z_{i}$ from the SVD method [10] is used as in Eq. (9).

$Z_{i}=\left|U 1_{i}\right|-\left|U 2_{i}\right|$

This modified version of principal component analysis consists of only one function, which is defined by the difference between the absolute values of the elements of the $U$ vectors. The maximum of this function suggests a tray for the location of the primary sensor, and the minimum of this function suggests another tray for the location of the secondary sensor. This method offers a slight advantage over the traditional SVD analysis, because it considers the interaction of the individual sensor locations in more detail. From Fig. 3, sensor locations are changed to the 4th and the 8th trays of the RD column. In Eqs. (7) and (8), $T_{\mathrm{n}}$ is the temperature of the $n$th tray, FR and RR are the $\mathrm{HAc} / \mathrm{EtOH}$ feed ratio and reflux ratio, respectively, $K$ is the gain matrix, $\Sigma$ is the diagonal matrix, $U$ is left singular vectors, and $V$ is right singular vectors.

The controller pairing suggestion for this dual-point control is from the relative gain array (RGA) analysis.

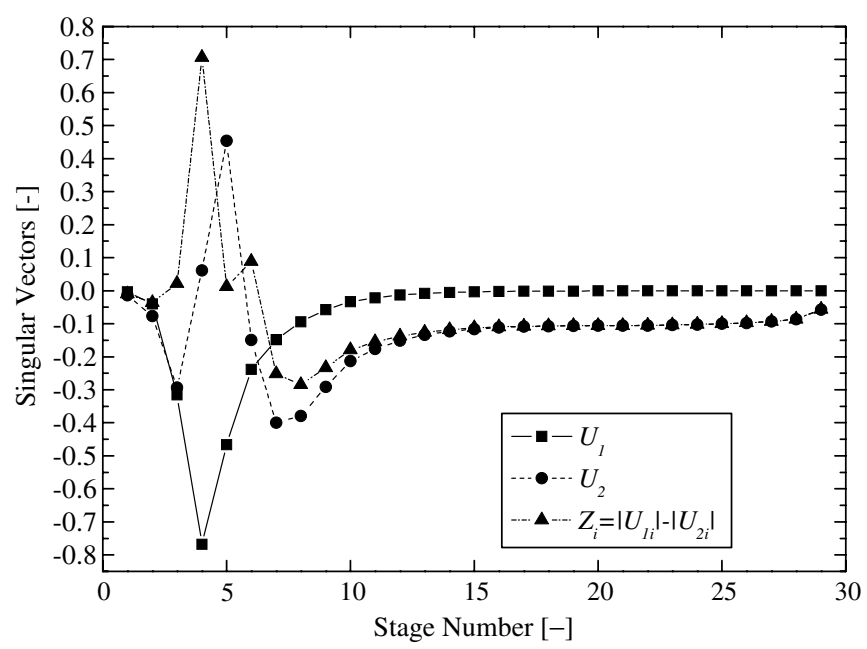

Fig. 3. Modified principal component analysis RD column [4].
The steady-state gains of this dual-point control are shown in Eq. (10). It is easy to obtain the RGA given in Eq. (11). From RGA, the controller pairings of this control use the organic reflux ratio to control the temperature of the 4th tray, and the fresh $\mathrm{HAc} / \mathrm{EtOH}$ feed ratio to control the temperature of the 8 th tray in the RD column.

$$
\begin{aligned}
& {\left[\begin{array}{l}
T_{\mathrm{RD}, 4} \\
T_{\mathrm{RD}, 8}
\end{array}\right]=\left[\begin{array}{cc}
29.8798 & -3.5273 \\
3.7275 & -0.0877
\end{array}\right]\left[\begin{array}{l}
\mathrm{FR} \\
\mathrm{RR}
\end{array}\right]} \\
& \mathrm{RGA}=\left[\begin{array}{cc}
-0.233 & 1.233 \\
1.233 & -0.233
\end{array}\right]
\end{aligned}
$$

\subsection{Tuning method}

Tuning the PID controller for the two interactive temperature loops in the RD column is quite time-consuming. The concept of an effective open-loop process described by Huang et al. [11] is used to obtain the open-loop model parameters for tuning the controller. The tuning procedure is to do positive and negative open-loop tests on one temperature loop while the other temperature loop in the RD column is under closed-loop control. The open-loop models from the positive and negative open-loop tests are averaged. After the open-loop model parameters are obtained from the test, the IMC-PI tuning rules described by Chien and Fruehauf [12] are used to obtain the tuning parameters. The IMC-PI closed-loop time constant was chosen as twice the process dead-time. After the tuning parameters of this loop are obtained, this loop is put into automatic control mode and an open-loop test is performed on the other loop. In this process, the tuning parameters of each case converge to the final values after three or fewer iterations of the above steps. The overall tuning parameters are given in Tables 2 and 3.

\subsection{Performance of the CSIA control scheme}

In this single-point control scheme, the organic reflux ratio is kept constant at the same value as that in the nominal base case. The controller tuning parameters are given in Table 2. The product dynamic responses of $\pm 20 \%$ throughput changes are shown in Fig. 4. The temperature of the trays in the RD column and the stripper column are controlled quickly and approximately at the setpoint values. From Fig. 4, both impurities of the final product returned to the required specifications. This simulation run shows that this simple control scheme is able to handle changes of throughput. In another closed-loop simulation, the dynamic responses of the HAc feed composition $\left(x_{\text {Feed,HAc }}\right)$ from 0.952 to 1 and from 0.952 to 0.9 are shown in Fig. 5. Although the temperatures of the trays in the RD column and in the stripper column are again returned to the setpoint values, the responses to the two final product impurities are not satisfactory. Especially the HAc content of the final EtAc product stream increases from $0.01 \mathrm{wt} . \%$ to $0.014 \mathrm{wt} . \%$, in other words, a $40 \%$ increase in the HAc 
Table 2

Controller parameters of single-point and dual-point scheme by open-loop and closed-loop sensitivity analysis

\begin{tabular}{|c|c|c|c|c|c|}
\hline $\begin{array}{l}\begin{array}{l}\text { Control } \\
\text { scheme }\end{array} \\
\end{array}$ & Controlled variable & Manipulated variable & $\begin{array}{l}\text { Control } \\
\text { scheme }\end{array}$ & Controlled variable & Manipulated variable \\
\hline $\mathrm{CS} 1 \mathrm{~A}$ & $\begin{array}{l}\text { RD 4th tray } \\
\text { temperature } \\
\text { Stripper 6th tray } \\
\text { temperature }\end{array}$ & $\begin{array}{l}\text { HAc/EtOH feed ratio } \mathrm{sp} \\
\left(K_{\mathrm{c}}=1.47, \tau_{\mathrm{I}}=526.5\right) \\
\text { Stripper reboiler duty }\left(K_{\mathrm{c}}=3.09\right. \\
\left.\tau_{\mathrm{I}}=8.17\right)\end{array}$ & CS1B & $\begin{array}{l}\text { RD 3rd tray } \\
\text { temperature } \\
\text { Stripper 8th tray } \\
\text { temperature }\end{array}$ & $\begin{array}{l}\text { HAc/EtOH feed ratio sp } \\
\left(K_{\mathrm{c}}=1.5, \tau_{\mathrm{I}}=480\right) \\
\text { Stripper reboiler duty } \\
\left(K_{\mathrm{c}}=13.27, \tau_{\mathrm{I}}=8.24\right)\end{array}$ \\
\hline $\mathrm{CS} 2 \mathrm{~A}$ & $\begin{array}{l}\text { RD 8th tray } \\
\text { temperature } \\
\text { RD 4th tray } \\
\text { temperature } \\
\text { Stripper 6th tray } \\
\text { temperature }\end{array}$ & $\begin{array}{l}\text { HAc/EtOH feed ratio } \mathrm{sp} \\
\left(K_{\mathrm{c}}=36.86, \tau_{\mathrm{I}}=230.9\right) \\
\text { Organic reflux ratio sp }\left(K_{\mathrm{c}}=8.78,\right. \\
\left.\tau_{\mathrm{I}}=5.2\right) \\
\text { Stripper reboiler duty }\left(K_{\mathrm{c}}=11.45,\right. \\
\left.\tau_{\mathrm{I}}=6.9\right)\end{array}$ & $\mathrm{CS} 2 \mathrm{~B}$ & $\begin{array}{l}\text { RD 8th tray } \\
\text { temperature } \\
\text { RD 3rd tray } \\
\text { temperature } \\
\text { Stripper 8th tray } \\
\text { temperature }\end{array}$ & $\begin{array}{l}\text { HAc/EtOH feed ratio sp } \\
\left(K_{\mathrm{c}}=12.96, \tau_{\mathrm{I}}=468\right) \\
\text { Organic reflux ratio } \mathrm{sp} \\
\left(K_{\mathrm{c}}=24.12, \tau_{\mathrm{I}}=2.2\right) \\
\text { Stripper reboiler duty } \\
\left(K_{\mathrm{c}}=15.75, \tau_{\mathrm{I}}=4.365\right) \\
\end{array}$ \\
\hline
\end{tabular}

Table 3

Controller parameters of conservative operating point scheme

\begin{tabular}{lll}
\hline Control scheme & Controlled variable & Manipulated variable \\
\hline Conservative operating point & RD column 6th tray temperature & Fresh HAc/EtOH feed ratio sp $\left(K_{\mathrm{c}}=3.41, \tau_{\mathrm{I}}=343.5\right)$ \\
& Stripper 6th tray temperature & Stripper reboiler duty $\left(K_{\mathrm{c}}=13.14, \tau_{\mathrm{I}}=8.27\right)$ \\
\hline
\end{tabular}
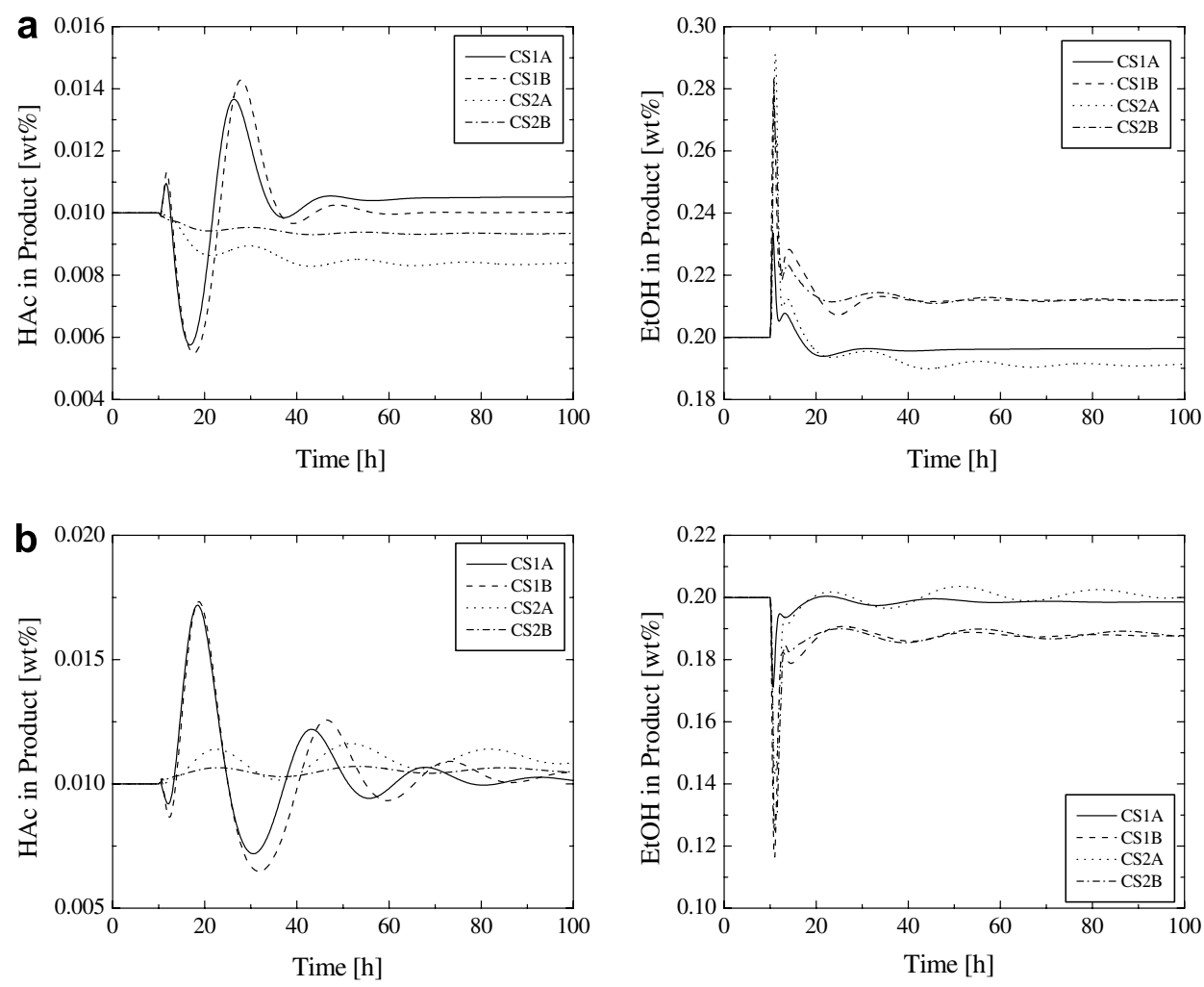

Fig. 4. Comparison of disturbance rejection for CS1A, CS2A, CS1B, and CS2B (a) throughput $+20 \%$, and (b) throughput $-20 \%$.

impurity. The result shows that this simple control scheme is not able to respond satisfactorily to feed composition fluctuations.

\subsection{Performance of the CS2A control scheme}

This control scheme uses a dual-point control in the RD column with the pairing mentioned earlier. The same throughput and HAc feed composition fluctuations are considered. Fig. 4 shows the dynamic responses to $\pm 20 \%$ changes in the EtOH feed flow-rate. The variations in the compositions of impurities of the final product for these two throughput changes are within the acceptable range.

The dynamic response of $x_{\mathrm{Feed}, \mathrm{HAc}}$ from 0.952 to 1 and from 0.952 to 0.9 are shown in Fig. 5. All temperature control points are returned to their set-points after this feed 

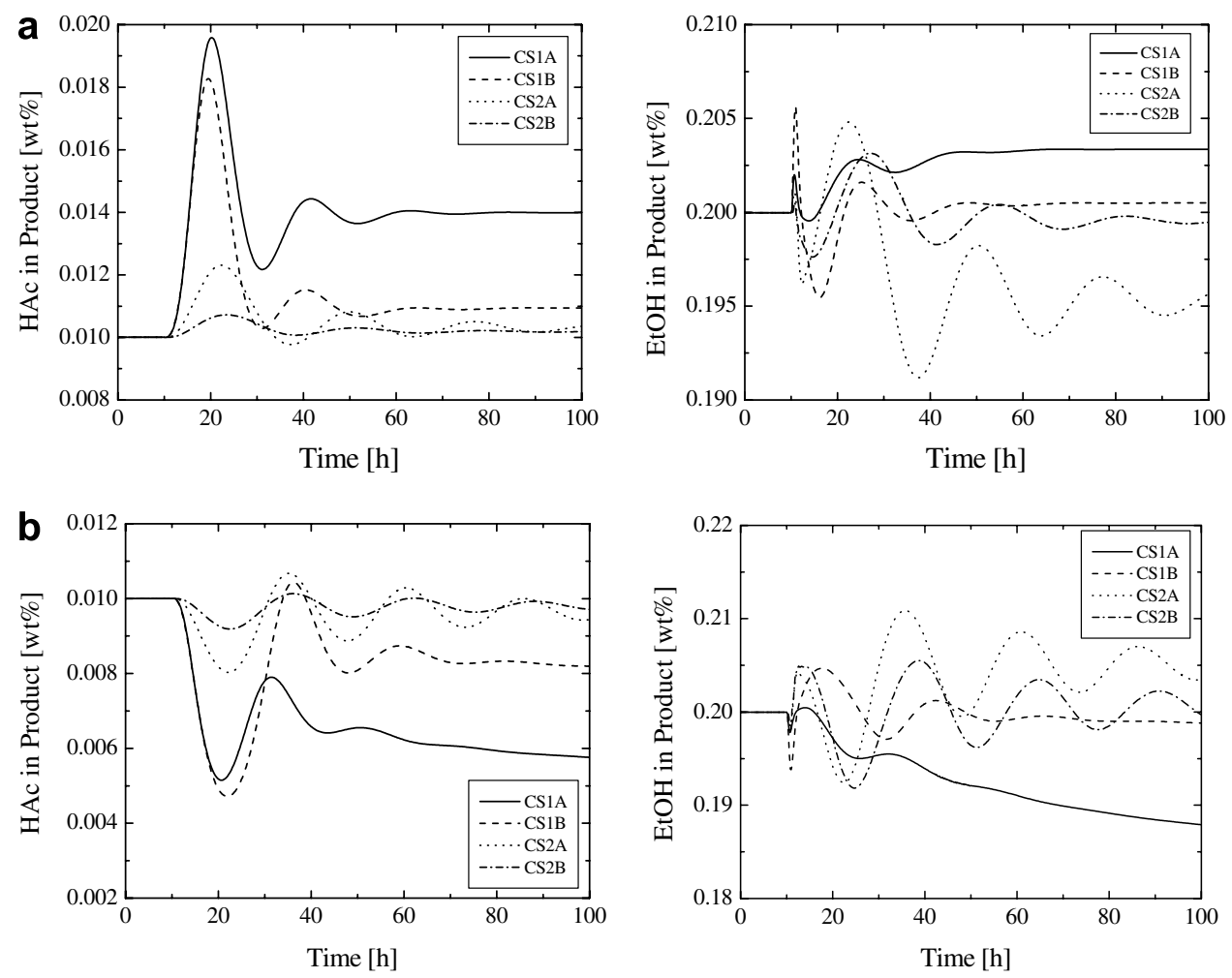

Fig. 5. Comparison of disturbance rejection for CS1A, CS2A, CS1B, and CS2B (a) $x_{\mathrm{HAc}, \text { Feed }}=1$, and (b) $x_{\mathrm{HAc}, \mathrm{Feed}}=0.9$.

composition change. More importantly, unlike the CS1A control scheme, the impurities of HAc and EtOH in the final product stream are all kept very close to the specifications. However, the system responses are more oscillatory and require approximately $200 \mathrm{~h}$ to settle at a new steady state.

\section{Development of alternative control schemes}

The control performances of the two control schemes discussed above have major disadvantages. In an attempt to overcome these disadvantages, new control schemes are considered. Two approaches are used to develop such new schemes. One is to move the original operating point of the base case to a more conservative one. The other is to select the locations of sensor(s) for feedback based on close-loop sensitivity analyses. The former is to depart from the optimal base case in exchange for better control. The latter one is to depart from the best open-loop sensitivity in exchange for less closed-loop sensitivity to fluctuations. In both cases, different trade-offs are made in order to increase the controllability of the system.

\subsection{Moving the operating point of CS1 A for better controllability}

The optimal base case is located as point $a$ in Fig. 6, which has the minimum total annual cost. In the CS1A scheme, the organic reflux flow-rate is considered as a design parameter but not as a manipulated variable. Although CS1A is simplest and capable of meeting product specification under throughput changes, the system has a large steady-state deviation, when the feed composition of HAc is perturbed. Notice that point $a$ is located at the most sensitive part of the curve in Fig. 6a, where reboiler duty affects the composition of HAc as an impurity in the steady state. There may be an alternative choice to increase the steady-state organic reflux flow-rate from $a$ $(42.27 \mathrm{~mol} / \mathrm{s})$ to $b(44 \mathrm{~mol} / \mathrm{s})$, as shown in Fig. 6, where the composition of HAc is less sensitive to the changes of reboiler duty. From Fig. 6a, the HAc impurity content decreases from $0.01 \mathrm{wt} . \%$ to $0.00136 \mathrm{wt} \% \%$ as the operating point moves from $a$ to $b$. Fig. 6b shows RD reboiler duty increases by about $3 \%$. In other words, an increase of the organic reflux flow-rate results in a decrease of the acid impurity and an increase of the RD reboiler duty. Even though Fig. 6c shows a small decrease of the stripper reboiler duty by this moving of the operating point, the increase in the rate of the RD reboiler duty is greater than the decreasing rate of the stripper reboiler duty. The RD column reboiler duty will dominate the operating cost and final total reboiler duties will increase by $2.5 \%$.

\subsubsection{Sensor location from open-loop sensitivity analysis}

Fig. 7 shows the open-loop sensitivity of the RD column and the stripper column to changes of the fresh $\mathrm{HAc} / \mathrm{EtOH}$ feed ratio, organic reflux ratio, and the stripper reboiler duty, respectively. From Fig. 7a, the HAc/EtOH feed ratio 

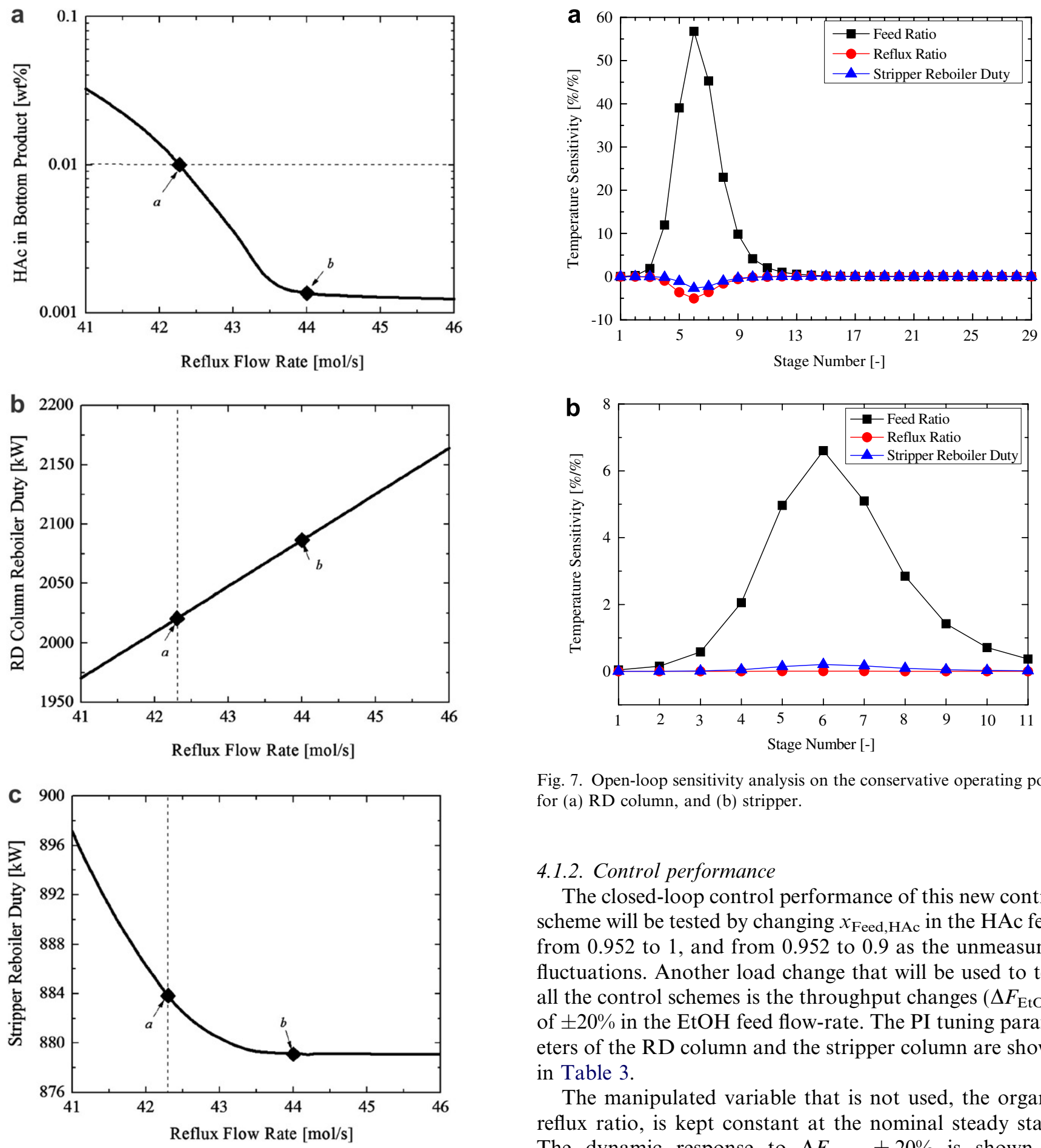

Fig. 6. Effects of operating point moving (a) HAc specification of product (b) RD reboiler duty, and (c) stripper reboiler duty.

has the largest effect on the temperatures at the 6th tray in the RD column. This means that the fresh $\mathrm{HAc} / \mathrm{EtOH}$ feed ratio can be manipulated to control the temperature at the 6 th tray in the RD column. Similarly, Fig. $7 b$ shows that the temperature of the 6th tray in the stripper column should be controlled by manipulating the stripper reboiler duty.

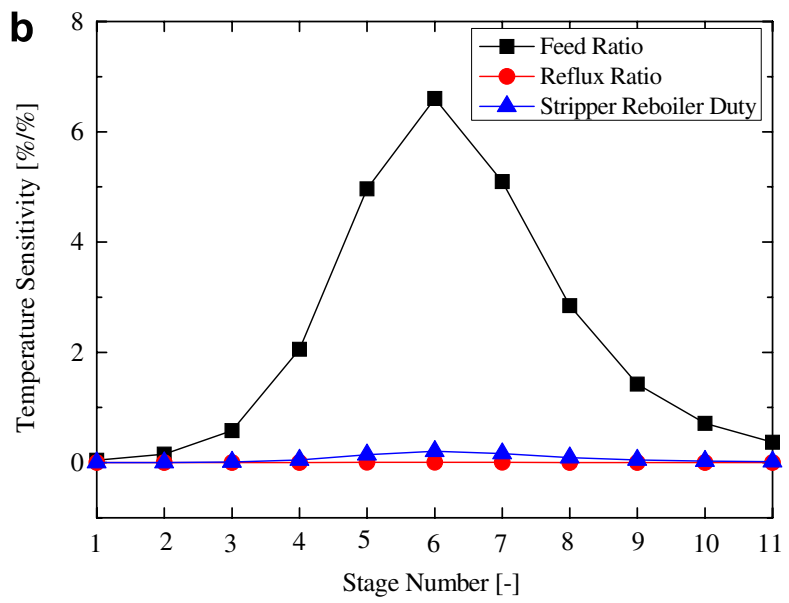

Fig. 7. Open-loop sensitivity analysis on the conservative operating point for (a) RD column, and (b) stripper.

\subsubsection{Control performance}

The closed-loop control performance of this new control scheme will be tested by changing $x_{\text {Feed,HAc }}$ in the HAc feed from 0.952 to 1 , and from 0.952 to 0.9 as the unmeasured fluctuations. Another load change that will be used to test all the control schemes is the throughput changes $\left(\Delta F_{\mathrm{EtOH}}\right)$ of $\pm 20 \%$ in the EtOH feed flow-rate. The PI tuning parameters of the RD column and the stripper column are shown in Table 3.

The manipulated variable that is not used, the organic reflux ratio, is kept constant at the nominal steady state. The dynamic response to $\Delta F_{\mathrm{EtOH}} \pm 20 \%$ is shown in Fig. 8. The temperatures of the trays in the RD column and in the stripper column are returned quickly to their set-point values. Also from the top two plots in Fig. 8, it is seen that the compositions of both final product impurities are within the specifications, despite these changes of throughput. This simulation run shows that this simple, single-point control scheme is able to handle $\Delta F$ fluctuation.

The dynamic responses of $x_{\mathrm{Feed}, \mathrm{HAc}}$ changes from 0.952 to 1 and from 0.952 to 0.9 are shown in Fig. 9. The temperatures of the trays in the RD column and in the stripper 


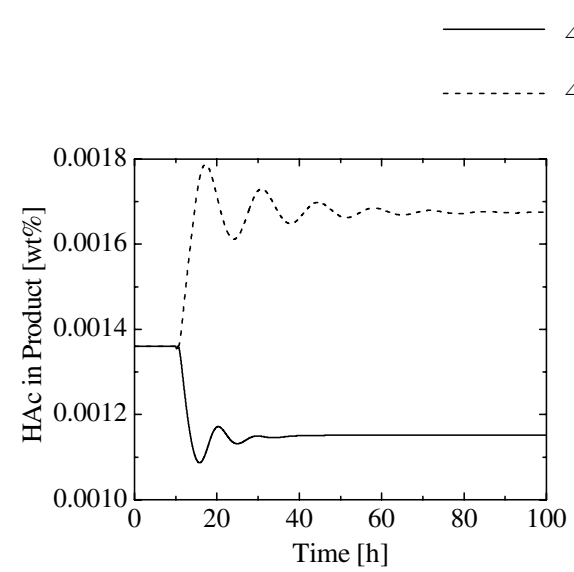

$$
\begin{aligned}
& \Delta F_{\text {ЁОН }}+20 \% \\
& \Delta F_{\text {ЁО }}-20 \%
\end{aligned}
$$
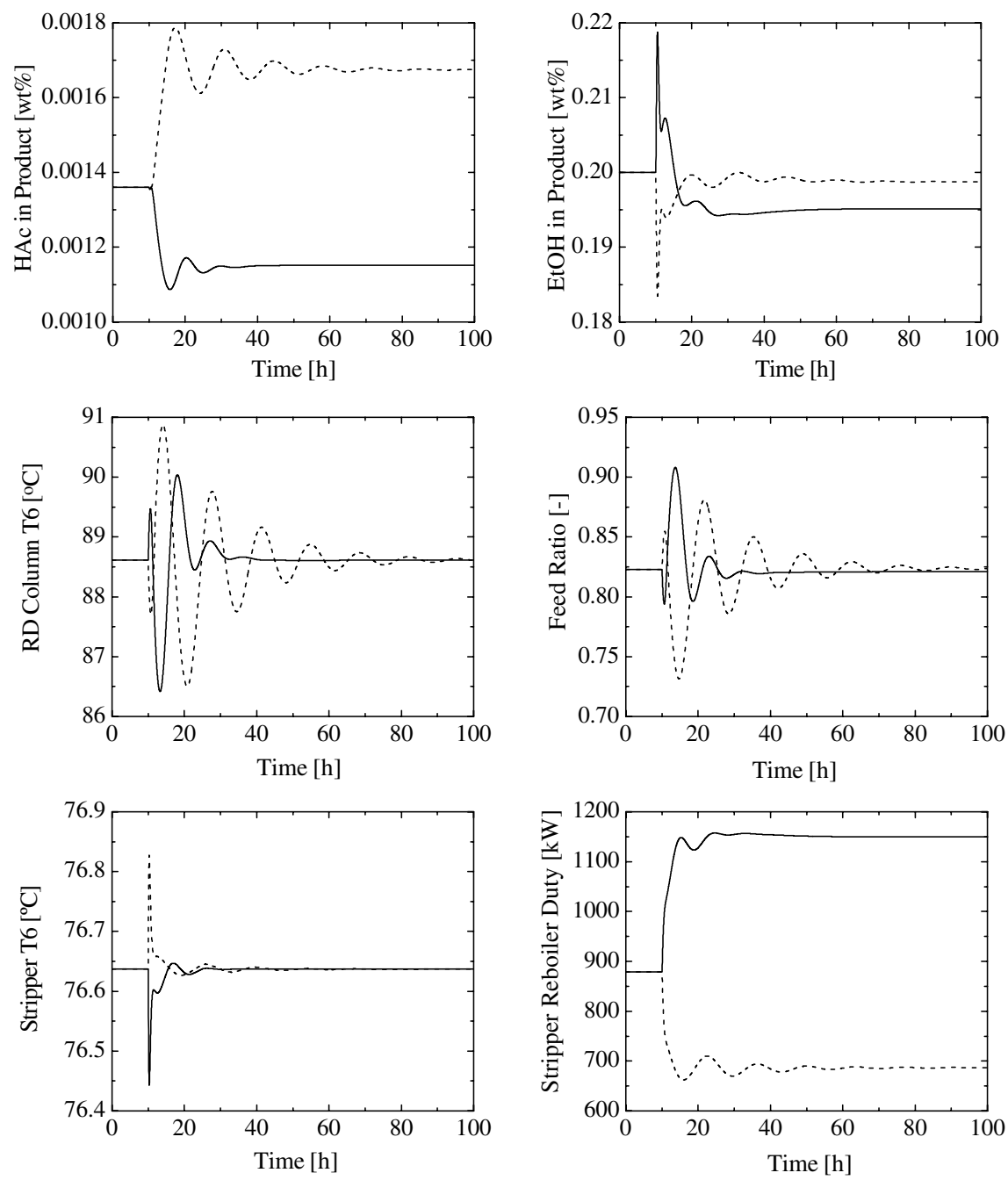

Fig. 8. Single-point control scheme with throughput disturbance on conservative operating point.

column are also quickly returned to the set-point values. Although the composition of HAc as an impurity in the final EtAc product stream increases by about $23 \%$, from 0.00136 to 0.00167 , at $x_{\text {Feed,HAc }}=1$, it is still less than the specification of $0.01 \mathrm{wt} . \%$. This illustrates that, by moving the operating point to a more conservative base case, the product specifications can be ensured despite load changes. However, the price to pay for this success is to increase the total annual cost (TAC) by $2.5 \%$.

\subsection{Moving sensor locations in original CS1A and CS2A}

In order to keep the operating point at the optimal base case, this section discusses how to improve the control responses and steady-state deviation by simply changing the control point(s) on the basis of closed-loop sensitivity analysis. Notice that the concentrations of the products are controlled indirectly by temperature control loops in both CS1A and CS2A. Whenever fluctuations enter the system, if the temperatures are controlled at their set-point values, there is no guarantee that the products will remain within specifications. By assuming that there are concentration loops with integral modes to keep the product concentrations within specifications, the temperature profiles in the column may be subject to change. The close-loop sensitivity of temperature at some point is then referred to the steady-state deviation of temperature at this point from its nominal value, while all the products are kept at their specification under closed-loop control. It would be desirable to have certain temperature locations where their closed-loop sensitivities to changes are at or close to zero. That means, by keeping the temperature of these points constant at set-points, the system may maintain the product within specifications when fluctuations occur, provided that their open-loop sensitivities are effective at these points. Thus, among all the potential sensor locations that 


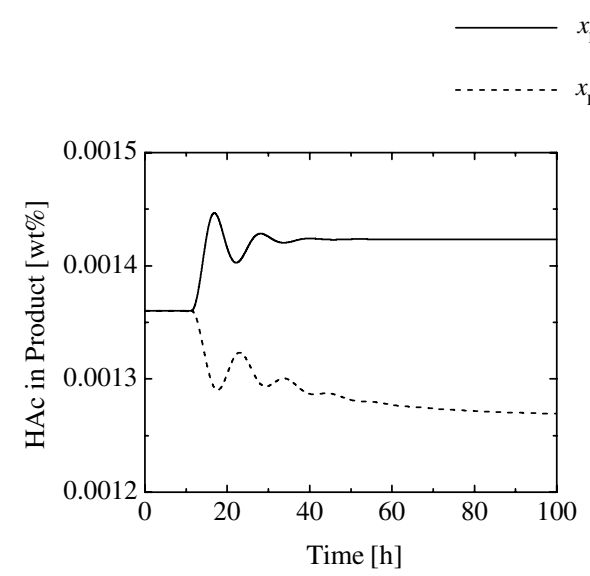

$x_{\text {Feed, } \text { HAc }}=1$

$x_{\text {Feed, HAc }}=0.9$
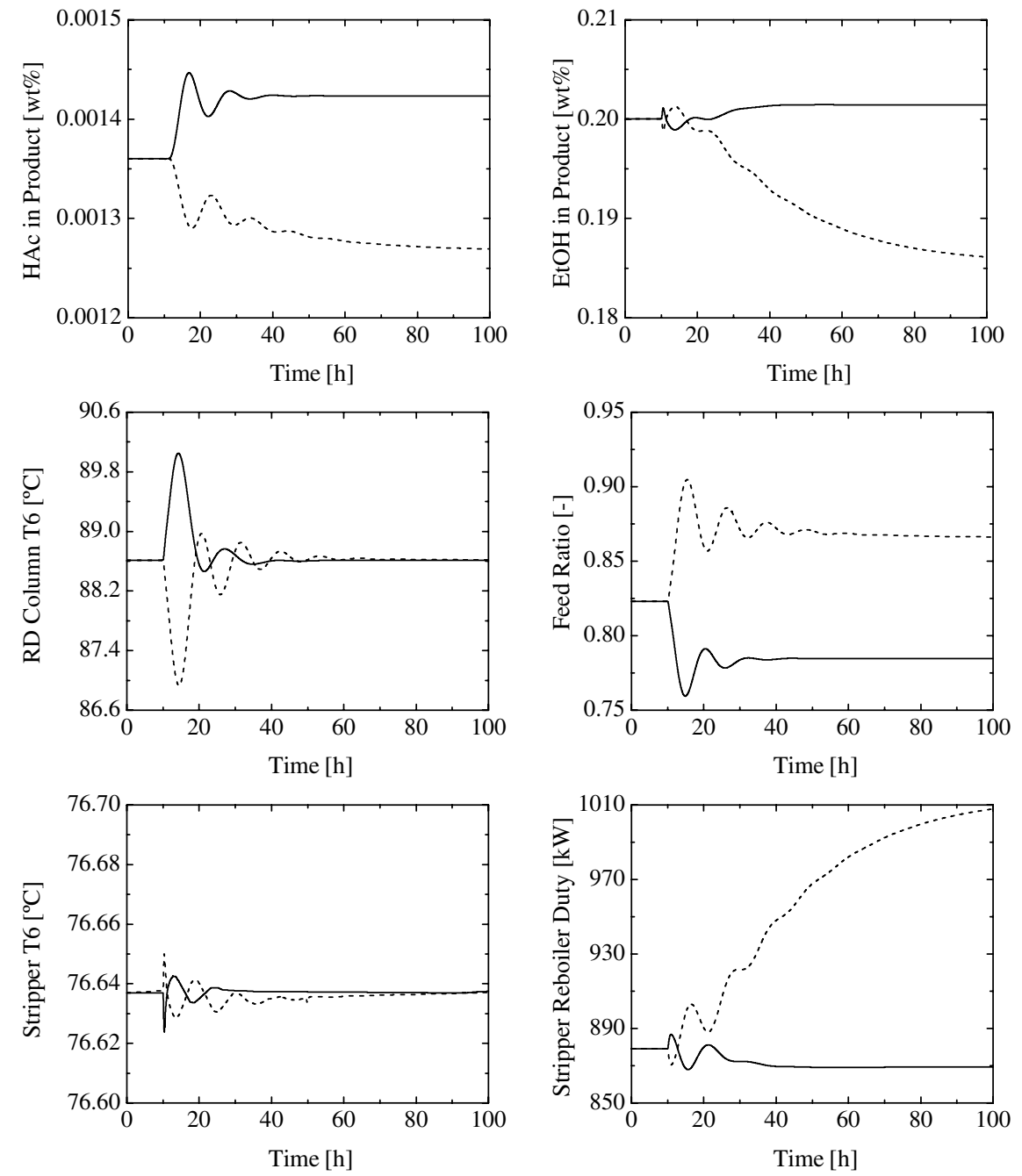

Fig. 9. Single-point control scheme with feed HAc composition disturbance on conservative operating point.

have very small (or zero) closed-loop sensitivities, the one with largest open-loop sensitivity should be chosen.

In the RD process studied here, the possible change of the composition of $x_{\text {Feed,HAc }}$ is considered to be within 1 and 0.9. Another possible load change of the $\Delta F_{\mathrm{EtOH}}$ is assumed to be within a range of $\pm 20 \%$. Thus, a feasible control scheme should be able to maintain the final product specifications at $<0.01 \mathrm{wt} . \% \mathrm{HAc}$ and $<0.2 \mathrm{wt} . \% \mathrm{EtOH}$. All the tuning parameters of single-point and dual-point control schemes with open-loop and closed-loop plus openloop sensitivity analysis are listed in Table 2.

\subsubsection{Closed-loop sensitivity analysis for sensor location}

For a single-point control scheme, the free variable, the organic reflux ratio, is fixed as a constant value, and the $\mathrm{HAc} / \mathrm{EtOH}$ feed ratio is used to meet the product specification of HAc content $<0.01 \mathrm{wt} . \%$, and the stripper reboiler duty is used to maintain the product specification of EtOH
$<0.2 \mathrm{wt.} \%$. The closed-loop sensitivity is studied by introducing a step change of HAc feed composition to the process which is under tight control to meet the above-mentioned specifications. Fig. 10 shows the closedloop sensitivity of each $x_{\mathrm{Feed}, \mathrm{HAc}}$ fluctuation in the RD column and in the stripper column, respectively.

From Fig. 10a, even though the 1st, 2nd, 11th, and 12th trays have the lowest closed-loop sensitivity, Fig. 2 reveals that they are insensitive in the open-loop test. Hence, the 3rd tray in the RD column is chosen as the new control point, because this tray still has a low closed-loop sensitivity and is near the 4th tray, which is most sensitive to change of the $\mathrm{HAc} / \mathrm{EtOH}$ feed ratio in the open-loop test.

Also from Fig. 10a, the temperature of the 4th tray is the most sensitive under closed-loop control. It means that the desired temperature setpoint of the 4th tray in the RD column should be altered to achieve the same product specifications. This explains why the HAc content of the CS1A 

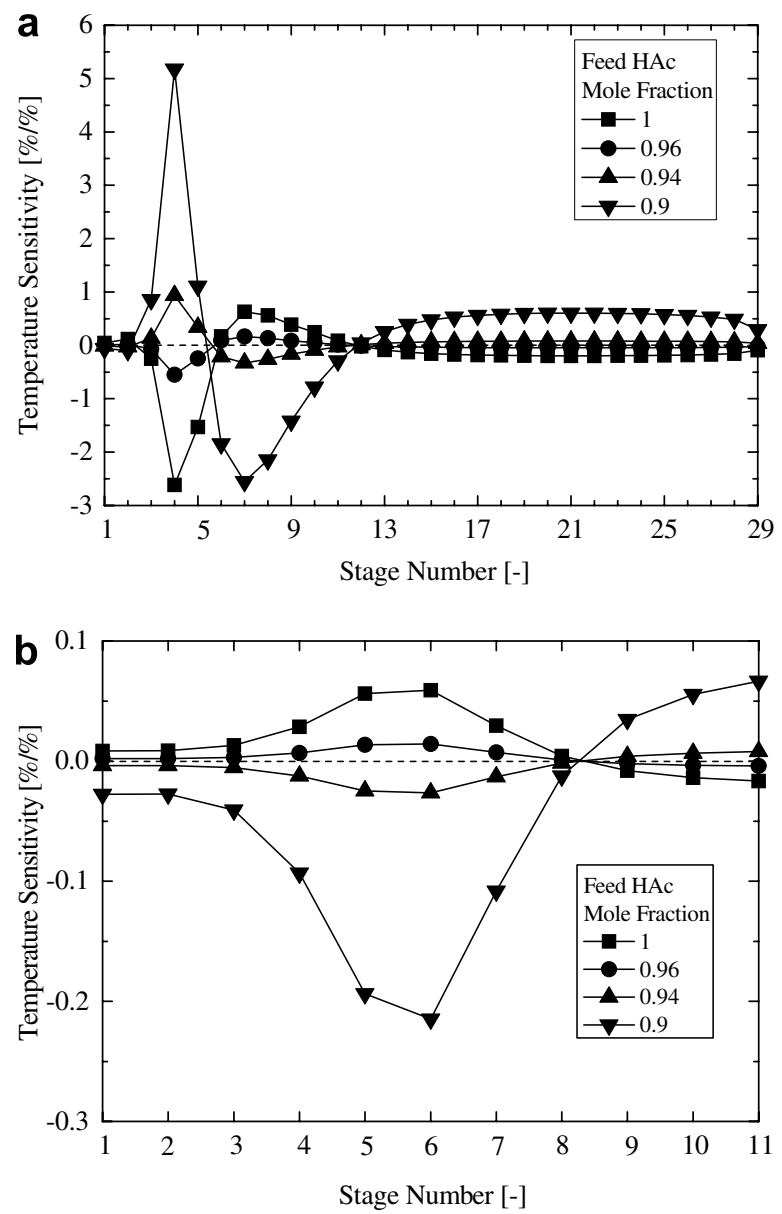

Fig. 10. Single-point control scheme closed-loop sensitivity test under feed HAc composition variation: (a) RD column and (b) stripper.

product has large steady-state deviation, which is designed by an open-loop sensitivity analysis method. For the stripper column, selection of the control point is easier than that in the RD column. Fig. 10b shows that the temperature of the 8th tray in the stripper column should be used as the control point by manipulating the stripper reboiler duty. The new single-point control scheme that controls the temperature of the 3rd tray in the RD column by manipulating the $\mathrm{HAc} / \mathrm{EtOH}$ feed ratio and controls the temperature of the 8th tray in the stripper column by manipulating the stripper reboiler duty is denoted as CS1B.

For dual-point control scheme, two product specifications are met by manipulating three variables. The HAc/ EtOH feed ratio is used to maintain the exact ratio of pure $\mathrm{HAc}$ and EtOH in the RD column manually, while the organic reflux ratio and stripper reboiler duty are used to meet the product specifications for the contents of HAc and $\mathrm{EtOH}$ in the product stream.

From Fig. 11a, the 3rd and 8th trays are chosen as the control points. For the reason discussed above, control points of the 1st and 2nd trays were not chosen because of the inadequate open-loop sensitivity. It is easy to choose the 8th tray as the control point for the stripper column from Fig. 11b. This new dual-point control scheme is
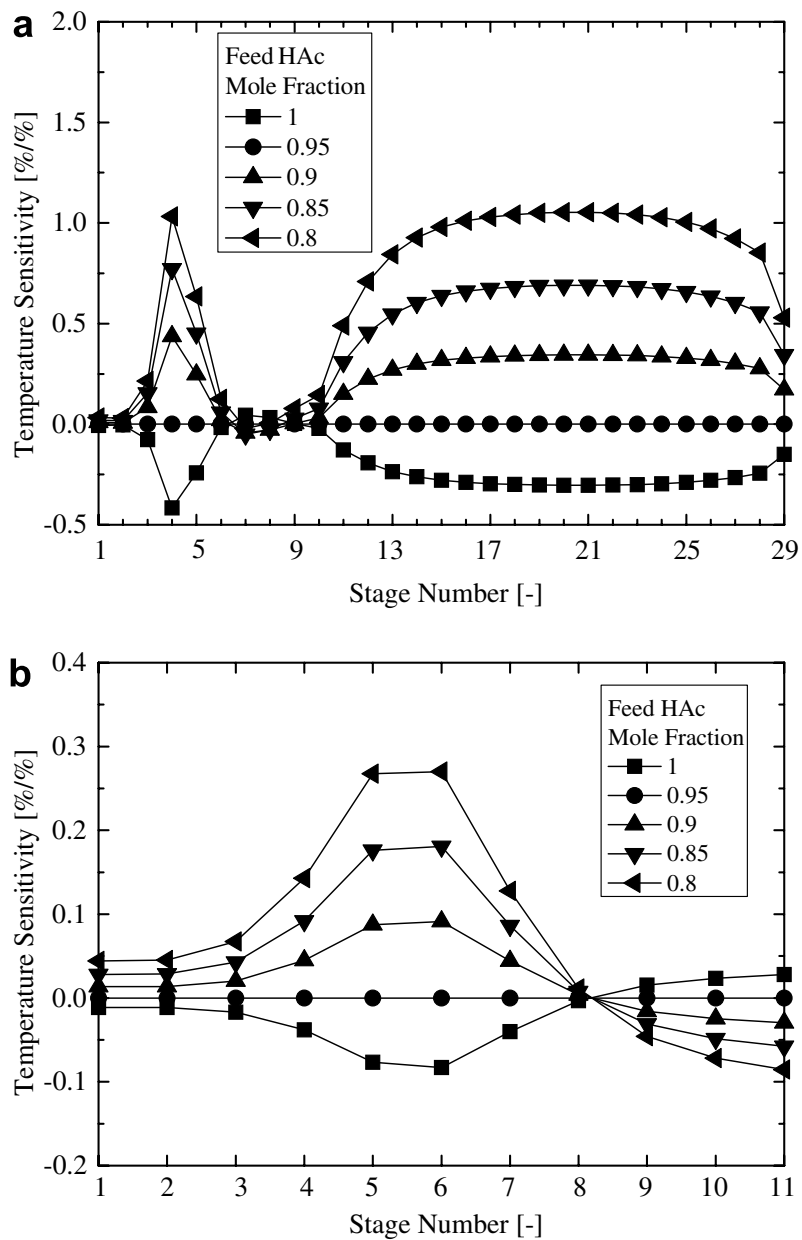

Fig. 11. Dual-point control scheme closed-loop sensitivity test under feed HAc composition variation: (a) RD column and (b) stripper.

denoted as CS2B. Fig. 11a also displays the same phenomenon as in Fig. 10a on the 4th tray. However, the magnitude of temperature deviation in Fig. 11a is smaller than that in Fig. 10a. It means that the steady-state deviation of HAc content in the product for CS2A should also be smaller than that for CS1A, and this is supported by the results in Figs. 4 and 5.

To analyze the selections of sensor location, some commonly used indices of the controllability for CS2A and CS2B control schemes are calculated. The RGA pairings of CS2B dual-control can be calculated by Eq. (12). The result of RGA as shown in Eq. (13) does not change with moving the RD column sensor locations from the 3rd to the 4th tray, and its magnitude is quite similar. However, the condition number $(\mathrm{CN})$ of $\mathrm{CS} 2 \mathrm{~A}$ with the value of 87.3093 is changed to 51.0105 with that of CS2B. For the $\mathrm{CS} 2 \mathrm{~B}$, the largest and smallest singular value $\left(\sigma_{1}=\right.$ $\left.12.8937, \sigma_{2}=0.2528\right)$ can be obtained by the SVD according to Eq. (7). The $\mathrm{CN}$ is the ratio of the largest to the smallest singular value. It is a measure of the relative difference between the strongest and the weakest directions of the system. In the physical sense, the $\mathrm{CN}$ represents the ratio of the maximum and minimum open-loop decoupled 
gains of the system. In the process, a larger $\mathrm{CN}$ indicates that it will be more difficult to use a dual-point control scheme. According to the above analysis, the closed-loop responses using CS2B can be expected to be better than those with CS2A.

$$
\begin{aligned}
& {\left[\begin{array}{l}
T_{\mathrm{RD}, 3} \\
T_{\mathrm{RD}, 8}
\end{array}\right]=\left[\begin{array}{cc}
12.2905 & -1.1637 \\
3.7275 & -0.0877
\end{array}\right]\left[\begin{array}{l}
\mathrm{FR} \\
\mathrm{RR}
\end{array}\right]} \\
& T_{\widehat{\mathrm{RD}}, 3} \quad T_{\widehat{\mathrm{RD}}, 8} \\
& \mathrm{RGA}=\left[\begin{array}{cc}
-0.3309 & 1.3309 \\
1.3309 & -0.3309
\end{array}\right] \mathrm{FR}
\end{aligned}
$$

\subsubsection{Control performance of the CSIB scheme}

This control scheme is a single-point control scheme that is almost the same as CS1A, except that the control point of the RD column is moved from the 4th to the 3rd tray and the control point of the stripper column is moved from the 6 th to the 8 th tray.

The dynamic response of $\Delta F_{\mathrm{EtOH}} \pm 20 \%$ changes is shown in Fig. 4. Notice that the EtOH content in the product stream increases by about $6 \%$. This is because the selection of the control point is based on the closed-loop analysis with the fluctuation from HAc feed content but not from throughput. The system dynamics of CS1B still exhibit a large overshoot, similar to that of CS1A. This is because open-loop and closed-loop sensitivity analysis methods reflect only the steady-state result, not the system dynamics.

The dynamic responses to the change of $x_{\mathrm{Feed}, \mathrm{HAc}}$ from 0.952 to 1 and from 0.952 to 0.9 are shown in Fig. 5. The contents of $\mathrm{HAc}$ and $\mathrm{EtOH}$ in the EtAc product stream are successfully returned to $<0.01 \mathrm{wt} . \%$ and $<0.2 \mathrm{wt} . \%$, respectively. This result shows that this simpler control scheme is able to properly reject feed composition fluctuations with only changes in the location of the sensor.

\subsubsection{Control performance of the CS2B scheme}

This control scheme is a dual-point control scheme almost the same as CS2A, using the $\mathrm{HAc} / \mathrm{EtOH}$ feed ratio to control the temperature of the 8th tray; however, another control point to manipulate the organic reflux ratio is moved from the 4th tray to the 3rd tray. Also, the stripper reboiler duty controls the temperature of the 8th tray instead of the 6th tray as in CS2A.

Fig. 4 shows the dynamic responses to $\Delta F_{\mathrm{EtOH}} \pm 20 \%$ changes for this control scheme. The variations of the HAc content in the product stream for the throughput changes are within the acceptable range; however, the overshoot phenomenon of EtOH content in the product stream is the same as in CS1B. The dynamic responses to $x_{\mathrm{Feed}}$, HAc from 0.952 to 1 and from 0.952 to 0.9 are shown in Fig. 5. The compositions of $\mathrm{HAc}$ and $\mathrm{EtOH}$ impurities in the final product stream are all kept very close to original specifications. However, there is still some oscillation in the closed-loop response, particularly for the case of $x_{\mathrm{Feed}, \mathrm{HAc}}$ from 0.952 to 0.9 .

\subsection{Comparisons of CS1A, CS1B, CS2A, and CS2B control schemes}

When subject to fluctuation from changes of $x_{\mathrm{Feed}, \mathrm{HAc}}$, Fig. 5 shows the responses from systems with four different control schemes. From this figure, it is found that the system with CS2B is most effective in reducing the deviations from the set-points of the impurity specifications. However, CS1B is better in terms of the closed-loop speed of response and settling time. Both systems with control schemes of CS1B and CS2B are capable of reducing the deviations. This agrees with the fact that the sensor location for feedback is taken from the analysis of closed-loop sensitivity to the $x_{\text {Feed,HAc }}$ changes.

If the change of throughput is the source of fluctuation, Fig. 4 shows the closed-loop responses with four different control schemes. Under $\Delta F_{\text {EtOH }} \pm 20 \%$ changes, moving the control point is still effective for suppressing the changes of the content of the HAc impurity in the product stream; however, the changes of the $\mathrm{EtOH}$ content in the product stream for CS1B and CS2B are larger. This is
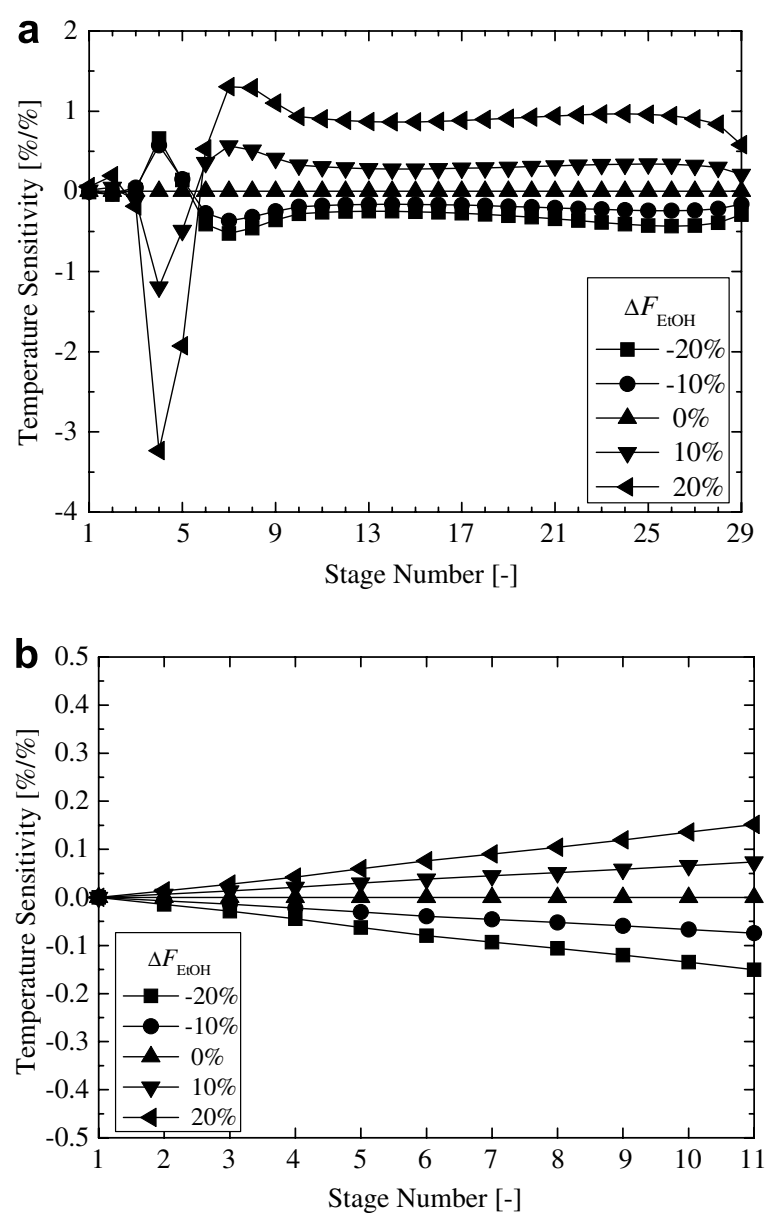

Fig. 12. Dual-point control scheme closed-loop sensitivity test under throughput variation: (a) RD column and (b) stripper. 
Table 4

Performance comparison by open-loop and closed-loop sensitivity analysis

\begin{tabular}{|c|c|c|c|c|c|}
\hline Disturbance & $\begin{array}{l}\text { Product } \\
\text { composition }\end{array}$ & $\begin{array}{l}\text { CS1A } \\
\text { RD } T_{4} \\
\text { Stripper } T_{6} \\
\end{array}$ & $\begin{array}{l}\text { CS1B } \\
\text { RD } T_{3} \\
\text { Stripper } T_{8} \\
\end{array}$ & $\begin{array}{l}\mathrm{CS} 2 \mathrm{~A} \\
\mathrm{RD} T_{4} \mathrm{RD} T_{8} \\
\text { Stripper } T_{6}\end{array}$ & $\begin{array}{l}\mathrm{CS} 2 \mathrm{~B} \\
\mathrm{RD} T_{3} \mathrm{RD} T_{8} \\
\text { Stripper } T_{8}\end{array}$ \\
\hline$x_{\text {Feed,HAc }}=1$ & $x_{\mathrm{EtOH}}$ & $\begin{array}{l}\text { Fast settling time } \\
\text { High overshoot } \\
40 \% \text { Deviation } \\
\text { Fast settling time } \\
\text { Low overshoot } \\
2 \% \text { Deviation }\end{array}$ & $\begin{array}{l}\text { Fast settling time } \\
\text { High overshoot } \\
10 \% \text { Deviation } \\
\text { Fast settling time } \\
\text { Low overshoot } \\
\text { No deviation }\end{array}$ & $\begin{array}{l}\text { Oscillatory } \\
\text { Low overshoot } \\
\text { Almost no deviation } \\
\text { Oscillatory } \\
\text { High overshoot } \\
2.5 \% \text { Deviation }\end{array}$ & $\begin{array}{l}\text { Little oscillatory } \\
\text { Very low overshoot } \\
\text { No deviation } \\
\text { Oscillatory } \\
\text { Low overshoot } \\
\text { Almost no deviation }\end{array}$ \\
\hline$x_{\text {Feed,HAc }}=0.9$ & $x_{\mathrm{EtOH}}$ & $\begin{array}{l}\text { Fast settling time } \\
\text { High overshoot } \\
(40 \% \text { deviation }) \\
\text { Fast settling time } \\
\text { Low overshoot } \\
5 \% \text { Deviation }\end{array}$ & $\begin{array}{l}\text { Fast settling time } \\
\text { High overshoot } \\
(20 \% \text { deviation }) \\
\text { Fast settling time } \\
\text { Low overshoot } \\
\text { No deviation }\end{array}$ & $\begin{array}{l}\text { Oscillatory } \\
\text { Low overshoot } \\
\text { Almost no deviation } \\
\text { Oscillatory } \\
\text { High overshoot } \\
2.5 \% \text { Deviation }\end{array}$ & $\begin{array}{l}\text { Little oscillatory } \\
\text { Very low overshoot } \\
\text { No deviation } \\
\text { Oscillatory } \\
\text { Low overshoot } \\
\text { Almost no deviation }\end{array}$ \\
\hline$\Delta F_{\mathrm{EtOH}}+20 \%$ & $\begin{array}{l}x_{\mathrm{HAc}} \\
x_{\mathrm{EtOH}}\end{array}$ & $\begin{array}{l}\text { Fast settling time } \\
\text { High overshoot } \\
5 \% \text { Deviation } \\
\text { Fast settling time } \\
\text { High overshoot } \\
\text { (2\% deviation) }\end{array}$ & $\begin{array}{l}\text { Fast settling time } \\
\text { High overshoot } \\
\text { No deviation } \\
\text { Fast settling time } \\
\text { High overshoot } \\
6 \% \text { Deviation }\end{array}$ & $\begin{array}{l}\text { Little oscillatory } \\
\text { Very low overshoot } \\
\text { (18\% deviation) } \\
\text { Little oscillatory } \\
\text { High overshoot } \\
\text { (4.5\% deviation) }\end{array}$ & $\begin{array}{l}\text { Little oscillatory } \\
\text { Very low overshoot } \\
\text { (5\% deviation) } \\
\text { Fast settling time } \\
\text { High overshoot } \\
6 \% \text { Deviation }\end{array}$ \\
\hline$\Delta F_{\mathrm{EtOH}}-20 \%$ & $\begin{array}{l}x_{\mathrm{HAc}} \\
x_{\mathrm{EtOH}}\end{array}$ & $\begin{array}{l}\text { Oscillatory } \\
\text { High overshoot } \\
\text { Almost no deviation } \\
\text { Fast settling time } \\
\text { High overshoot } \\
\text { Almost no deviation }\end{array}$ & $\begin{array}{l}\text { Oscillatory } \\
\text { High overshoot } \\
5 \% \text { Deviation } \\
\text { Fast settling time } \\
\text { High overshoot } \\
\text { (6\% deviation) }\end{array}$ & $\begin{array}{l}\text { Oscillatory } \\
\text { Low overshoot } \\
10 \% \text { Deviation } \\
\text { Little oscillatory } \\
\text { High overshoot } \\
\text { Almost no deviation }\end{array}$ & $\begin{array}{l}\text { Little oscillatory } \\
\text { Very low overshoot } \\
5 \% \text { Deviation } \\
\text { Fast settling time } \\
\text { High overshoot } \\
\text { (6\% deviation) }\end{array}$ \\
\hline Operability range & & Narrow & Narrow & Wider & Wider \\
\hline
\end{tabular}


because the closed-loop sensitivity analysis is not based on the throughput fluctuation. Fig. 12 shows the closed-loop sensitivity analysis for $\Delta F_{\mathrm{EtOH}}$ changes. According to Fig. 12a, it is appropriate that the 3rd tray is selected as the control point with the $\Delta F_{\mathrm{EtOH}}$ changes. This choice of the control point is consistent whether the closed-loop sensitivity analysis is based on the $x_{\text {Feed,HAc }}$ fluctuation or the throughput fluctuation. However, according to Fig. 12b, the temperature of the 8th tray in the stripper column is a worse control point than the temperature of the 6th tray because its temperature closed-loop sensitivity is larger than that of the 6th tray. This is why the EtOH content has the larger deviation for CS1B and CS2B in Fig. 4. For the overall comparisons, moving sensor locations by the closed-loop sensitivity analysis is still better than by the traditional method of open-loop sensitivity analysis. The detail comparisons of these four control schemes are shown in Table 4. Notice that the percentage of deviations in parentheses indicates that the final product composition is better than the specification.

\section{Feasible region of disturbances for effective control}

In this section, the feasible region of disturbances for effective control is studied for different control schemes. The disturbances considered here are the changes of alcohol feed flow-rate and the changes of composition of HAc feed. It is assumed that the EtOH feed composition $x_{\text {Feed,EtOH }}$ remains the same as that of the nominal case, and the EtOH feed flow-rate is used as the throughput manipulator. To each given feed flow-rate of $\mathrm{EtOH}$, the $x_{\text {Feed,HAc }}$ has a feasible range for effective control. That means, within this range, the control system can effectively keep the product within specifications. On the other hand, if the $x_{\text {Feed,HAc }}$ is down below this feasible region, the temperature loops will be out of control, because of the snowball effect and the limitation of the column capacity. By tracing out this controllable range of $x_{\mathrm{Feed}, \mathrm{HAc}}$ along the EtOH flow-rate within $\pm 20 \%$ of its nominal value, a feasible region of disturbances for control can be obtained. For changes of the EtOH feed flow-rate larger than $20 \%$, it is reasonable to assume that the base case needs to be redesigned. Fig. 13 shows the lowest value of $x_{\mathrm{Feed}}$, HAc that each control scheme can handle. From Fig. 13a and b, CS1A and CS1B have almost the same operating ranges, which are much narrower than those for CS2A and CS2B. From the steady-state viewpoint, when $x_{\mathrm{Feed}, \mathrm{HAc}}$ decreases, the organic flow-rate will increase to carry additional water from the feed to the top of RD column. The occurrence of snowball effect above-mentioned will be explained as follows. Because CS1A and CS1B fix the organic reflux ratio, the actual organic reflux flow increases when $x_{\text {Feed,HAc }}$ becomes lower. When $x_{\mathrm{Feed}, \mathrm{HAc}}$ to the RD column is lowered to a certain limit, more water is recycled back to the RD column. As a result, the RD temperature control action will be triggered to achieve the original stoichiometric balance. When there is more water in the feed,
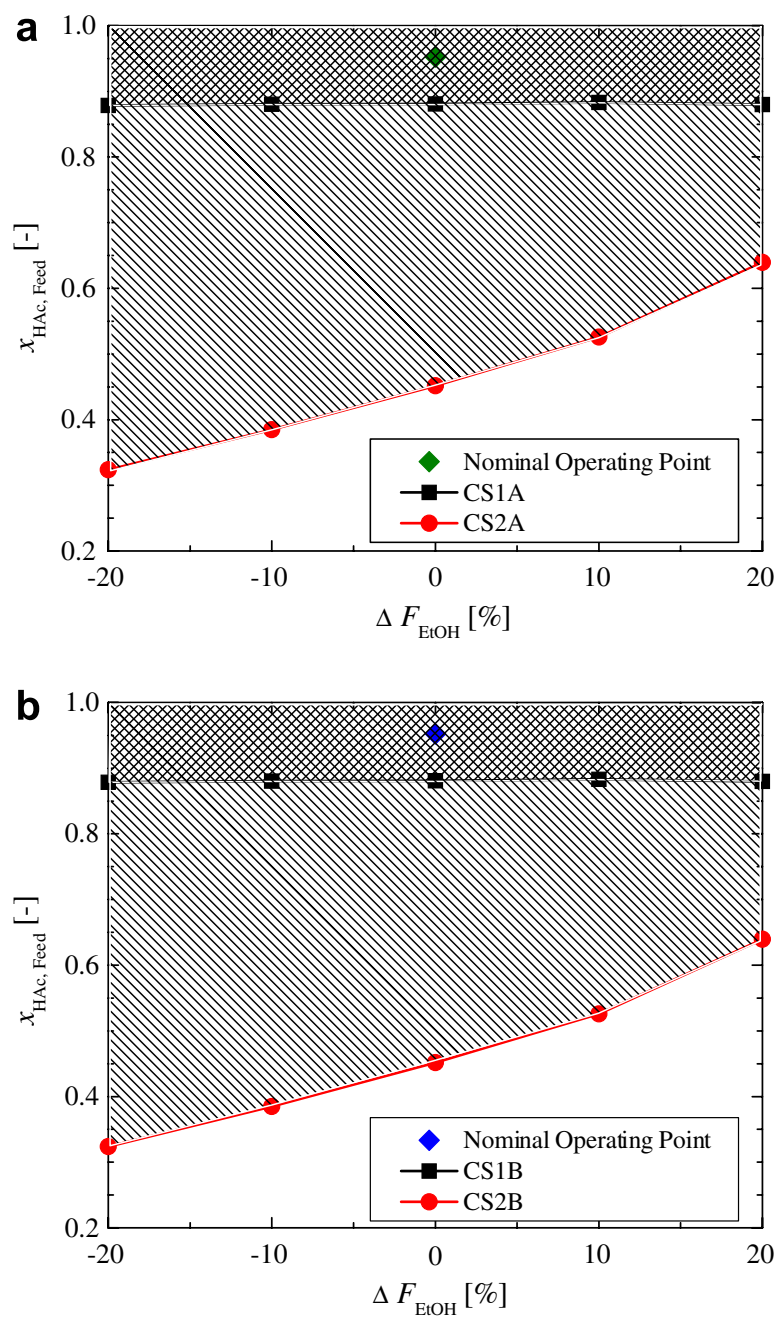

Fig. 13. Feasible range of disturbances for effece control (a) CS1A and CS2A, (b) CS1B, and CS2B for throughput $\pm 20 \%$, and HAc feed disturbance.

more water will be carried to the top of the column and make the levels of the organic phase and the water phase increase. Because the reflux ratio is fixed in this case, the level control will make the organic reflux flow and the organic outlet flow to the stripper column increase. By this increase of organic outlet flow to the stripper column, the stripper heat duty needs to be increased because of the temperature control in the stripper and, hence, the recycled feed to the decanter also increases. As a result, even more water enters the decanter from two sources as positive feedback and a snowball effect occurs. This snowball effect will not happen in the case when $x_{\mathrm{Feed}, \mathrm{HAc}}$ increases.

Unlike a single-point control scheme, a dual-point control scheme uses the organic reflux ratio to control the temperature of another tray in the RD column. When lower $x_{\text {Feed,HAc }}$ occurs, the organic reflux ratio can be adjusted to eliminate the snowball effect caused by the top recycle stream from the stripper column, and the RD column is able to sustain greater changes of $x_{\mathrm{Feed}, \mathrm{HAc}}$. The feed to the stripper column also does not need to increase as much, 
due to increase of the organic reflux ratio by the additional temperature loop.

According to the controllable region in Fig. 13, if $x_{\text {Feed,HAc }}$ is greater than 0.88 , a single-point control scheme that has a shorter settling time and less oscillatory response can be applied to this process. On the other hand, if $x_{\text {Feed,HAc }}$ may be less than 0.88 , only a dual-point control scheme can be chosen. However, in this case, a closed-loop response will become more oscillatory.

According to the above results, the organic reflux ratio is an important variable for expanding the operability range for this process. This means also that another single-point control scheme with feedforward control can be considered. To apply this scheme and combining the advantages of single-point and dual-point control, the dynamic effects and models of fluctuation need to be obtained. For the throughput fluctuation, it can be measured easily by flow measurement. However, the fluctuation in $x_{\text {Feed,HAc }}$ is generally not measured and cannot feedforwarded to manipulate the organic reflux ratio. From a steady-state viewpoint, the $\mathrm{HAc} / \mathrm{EtOH}$ feed ratio will change to maintain the stoichiometric balance of the reactants, when the $x_{\text {Feed,HAc }}$ fluctuates. The controller output of a single-point control scheme can be treated as a feedforward signal to adjust the organic reflux ratio.

\section{Conclusions}

We present alternative ways to improve control of an EtAc reactive distillation process. The two control schemes recommended by Tang et al. [4], although workable, have their control drawbacks. The closed-loop dynamic response of the single-point control scheme is very fast; however, there is steady-state deviation in the impurity content of the final product as compared to product specifications. For the dual-point control scheme, although the deviation problem in the product impurity is improved, the closed-loop transient response is rather oscillatory and needs quite a long time to settle. Four alternative ways to control this system are proposed here.

The first way is to move the operating condition to a more conservative point. At this more conservative operating point, a simple single-point control scheme can be used to obtain faster closed-loop settling time without oscillation. The product specifications can be ensured despite load changes. However the price to pay is that the operating cost is increased by $2.5 \%$.

In order to save energy by maintaining the operating point at the original steady state, we propose a combination of open-loop and closed-loop sensitivity analysis methods to select locations for temperature feedback control. Traditionally, locations with maximum temperature variations in an open-loop sensitivity analysis are selected for temperature feedback. Here, the tray with minimum temperature variations in a closed-loop sensitivity test is selected instead. The closed-loop sensitivity is studied by introducing a step change of HAc feed composition to the process which is under tight control. It is found that, while subject to changes in feed composition of acid or production flow-rate, a design using an open-loop sensitivity method results in larger overshoot and deviation from the steady state in the closed-loop response. The proposed strategy based on closed-loop plus open-loop sensitivity analysis is found to be effective in decreasing the deviation from the steady state and to have good control performance.

As a result of the analysis of range feasible for control above mentioned, if $x_{\text {Feed,HAc }}$ is greater than 0.88 , the single-point control scheme CS1B, which has a faster settling time and less oscillatory response, can be applied to this process. On the other hand, if $x_{\text {Feed,HAc }}$ varies and has a value of less than 0.88 , the dual-point control scheme $\mathrm{CS} 2 \mathrm{~B}$ is recommended. However, in this case the closedloop response will inevitably become more oscillatory.

\section{Acknowledgment}

This work is supported by the Ministry of Economic Affair under grant 92-EC-17-A-09-S1-019.

\section{References}

[1] R.J. Burkett, D. Rossiter, Choosing the right control structure for industrial distillation columns, Proc. Process Control Instrum. 2000 (2000) 38-42.

[2] N. Vora, P. Daoutidis, Dynamic and control of an ethyl acetate reactive distillation column, Ind. Eng. Chem. Res. 40 (2001) 833-849.

[3] Y.T. Tang, H.P. Huang, I.-L. Chien, Design of a complete ethyl acetate reactive distillation system, J. Chem. Eng. Jpn. 36 (2003) 1352-1363.

[4] Y.T. Tang, H.P. Huang, I.-L. Chien, Plant-wide control of a complete ethyl acetate reactive distillation process, J. Chem. Eng. Jpn. 38 (2005) 130-146.

[5] J.G. Hayden, J.P. O'Connell, A generalized method for predicting second virial coefficients, Ind. Eng. Chem. Process Des. Dev. 14 (1975) 209-216.

[6] K. Alejski, F. Duprat, Dynamic simulation of the multicomponent reactive distillation, Chem. Eng. Sci. 51 (1996) 4237-4252.

[7] Aspen Plus, Release AspenONE, Aspen Technology, Inc., Cambridge, MA, USA, 2004.

[8] Aspen Dynamics, Release AspenONE, Aspen Technology, Inc., Cambridge, MA, USA, 2004.

[9] R. Krishna, Reactive separations: more ways to skin a cat, Chem. Eng. Sci. 57 (2002) 1491-1504.

[10] W.L. Luyben (Ed.), Practical Distillation Control, Van Nostrand Reinhold, New York, USA, 1992, pp. 151-152.

[11] H.P. Huang, J.C. Jeng, C.H. Chiang, W. Pan, A direct method for multi-loop PI/PID controller design, J. Process Control 13 (2003) 769-786.

[12] I.-L. Chien, P.S. Fruehauf, Consider IMC tuning to improve controller performance, Chem. Eng. Prog. 86 (1990) 33-41. 